\title{
Habitação de Interesse Social e o Minha Casa Minha Vida - faixa 1: questão ambiental na produção habitacional
}

\author{
Social Housing and the Minha Casa Minha Vida Program - range 1: \\ environmental issue in housing production
}

Isabel Cristina Nunes de Sousa[a] (D), Roberto Braga[a] (D)

[a] Universidade Estadual Paulista (Unesp), Instituto de Geociências e Ciências Exatas, Rio Claro, SP, Brasil

Como citar: Sousa, I. C. N., \& Braga, R. (2020). Habitação de Interesse Social e o Minha Casa Minha Vida - faixa 1: questão ambiental na produção habitacional. urbe. Revista Brasileira de Gestão Urbana, 12, e20190312. https://doi.org/10.1590/2175-3369.012.e20190312

\section{Resumo}

A proposta deste estudo incorpora, na análise da inserção urbana dos conjuntos produzidos pelo Programa Minha Casa Minha Vida (PMCMV), um olhar ambiental à discussão habitacional. Assim, buscou-se compreender como o atendimento às demandas sociais de habitação dialoga com a proteção ambiental. Objetivou-se, portanto, fazer uma análise da vinculação entre os efeitos ambientais e socioespaciais da implantação de empreendimentos do PMCMV - Faixa 1, em uma cidade média do interior paulista. 0 intuito foi contribuir para discussões acerca dos processos de provisão habitacional a partir de uma perspectiva ambiental, relacionando condicionantes do meio físico às estratégias de produção de cidade. Por meio de um estudo de caso, identificou-se a intensificação na ocupação de áreas ambientalmente impróprias à urbanização pela provisão habitacional via financiamento público. Essa conjuntura revela uma desarticulação entre funções social e ambiental, bem como entre políticas urbanas e habitacionais.

Palavras-chave: Conjuntos habitacionais. Fragilidades ambientais. Instrumentos urbanísticos. Vazios urbanos. Política habitacional.

\begin{abstract}
This work aimed to incorporate an environmental viewpoint into the social housing discussion through the urban insertion analysis of the housing complexes produced by the PMCMV. Therefore, it sought to understand how the demands of social housing dialogue with environmental protection. Thus, it was analyzed the link between the implementation of the first range PMCMV housing developments in a medium-sized city in the State of São Paulo, and its environmental and socio-spatial effects. It aimed to contribute to the discussions on the social housing provision process, from an environmental perspective, linking the physical conditions to city production strategies. Through a case study, it was identified an increase in the occupation of improper environmental areas, due to housing provision via public financing. This reveals a detachment between social and environmental function, as well as urban and housing policies.
\end{abstract}

Keywords: Mass-housing complexes. Environmental fragilities. Urban instruments. Urban voids. Housing policy.

ICNS é gestora e analista ambiental, mestre em Engenharia Urbana, doutoranda em Geografia, e-mail: icn.sousa@unesp.br RB é doutor em Geografia Humana, livre-docente em Planejamento Urbano e Regional, e-mail: rbraga@rc.unesp.br 


\section{Introdução}

Nas cidades, o acesso à moradia vincula-se à questão ambiental (Freitas, 2014). As ocupações informais frequentemente ocorrem em áreas ambientalmente fragilizadas, com precárias condições de habitabilidade e características biofísicas que desestimulam a urbanização formal (Freitas, 2014). Inadequadas do ponto de vista ambiental, essas áreas também são constantemente destinadas a empreendimentos habitacionais de interesse social.

A precariedade locacional ocorre nas cidades brasileiras desde a década de 1960, com o Banco Nacional de Habitação - BNH (Gondim, 2012; Ferreira et al., 2019). Isso se repetiu em muitos dos empreendimentos financiados via Programa Minha Casa Minha Vida - PMCMV (Brasil, 2009a), com reprodução da tendência de ocupação de áreas com restrições ambientais estabelecidas pela legislação, especialmente entre os empreendimentos Faixa 11. Nessa categoria, houve a ocupação de territórios marcados por fragilidades ambientais e/ou em áreas menos valorizadas e próximas a setores com maiores níveis de vulnerabilidade social (Rufino, 2015). Foram identificados, por exemplo, casos de empreendimentos em "[...] área de inundação, próximo a Áreas de Preservação Permanente (APP), em áreas de alta declividade e em topo de morro" (Rufino, 2015, p. 65). Análogo ao ocorrido em Araraquara-SP, onde empreendimentos do PMCMV - Faixa 1 foram construídos sobre Áreas de Proteção e Recuperação de Mananciais - APRM, “[...] interferindo diretamente com o zoneamento para preservação e recuperação dos recursos hídricos" (Menzori \& Falcoski, 2016, p. 7).

Tal realidade compõe um padrão periférico de urbanização, “[...] socialmente excludente e ambientalmente predatório" (Freitas, 2014, p. 113). Essa circunstância se atrela não somente à inabitual utilização de condicionantes ambientais para aprovação de empreendimentos habitacionais de interesse social (Scheidt et al., 2010), como também à definição dos locais de implantação em consonância com os interesses do mercado imobiliário, com o poder público municipal não interferindo no direcionamento das áreas prioritárias (Honda, 2013).

Nesse sentido, o desempenho das prefeituras municipais na operação de programas habitacionais pode ser positivo ou negativo. As gestões municipais podem tanto regular instrumentos urbanísticos, como as Zonas Especiais de Interesse Social - ZEIS, e garantir localizações mais adequadas para Habitação de Interesse Social - HIS (Jesus \& Denaldi, 2018), quanto ser consideradas corresponsáveis pela produção de conjuntos habitacionais distantes e desprovidos de urbanidade (Ferreira, 2014). Desta forma, Jesus \& Denaldi (2018) indicam o papel do município na "[...] aplicação de instrumentos urbanísticos redistributivos e voltados para ampliar o acesso à terra", mas reconhecem que tais instrumentos são limitados, “[...] principalmente, no caso de desenhos de programas como o PMCMV, que tem o setor privado como principal protagonista, e esse, de certa forma, define a localização da produção" (Jesus \& Denaldi, 2018, p. 82).

As ZEIS se destacam dentre os instrumentos urbanísticos para viabilização do acesso à moradia para a população de baixa renda. Previstas no Estatuto da Cidade (Brasil, 2001), mas implementadas em alguns municípios brasileiros antes da Constituição Federal de 1988 (Goulart et al., 2016), tratam-se de uma categoria de zoneamento urbano com padrão urbanístico próprio e diferenciado (Rolnik, 2010). As ZEIS se dividem, basicamente, em duas tipologias (não obrigatórias e passíveis de ampliação): áreas ocupadas por população de baixa renda em assentamentos precários e áreas vazias ou subutilizadas, "[...] com destinação predominante para a produção de HIS" (Brasil, 2009b, p. 18).

As ZEIS de áreas ocupadas são apropriadas para regularização fundiária, possibilitando o acesso à terra urbanizada pela população de baixa renda ${ }^{2}$ (Ferreira \& Motisuke, 2007). Já a demarcação de ZEIS em vazios urbanos permite induzir o aproveitamento de áreas desocupadas ou ociosas para implementação de programas habitacionais de interesse social. Embora a demarcação de ZEIS não

\footnotetext{
${ }^{1}$ Destinado à população com faixa de renda entre zero e três salários mínimos (Fase 1) ou até R\$1.600,00 (Fase 2).

2 Ainda assim, existem ocasiões em que os propósitos iniciais desse instrumento são deturpados, como no caso de Ipatinga-MG, em que ZEIS foram destinadas à população de menor renda familiar ou que vivesse em condições precárias de habitabilidade, mas também foram definidas como áreas irregularmente ocupadas por populações de média e alta rendas (Soares et al., 2012).
} 
resulte diretamente na construção de HIS, tal zoneamento "[...] é um estímulo para fornecer reservas de terra para a construção de moradias sociais, bem como um meio para facilitar o acesso à terra urbana" (Ribeiro et al., 2016, p. 454, tradução própria). A criação de uma reserva (estoque de terras) poderia, em longo prazo, interferir na lógica de preços no mercado imobiliário (Rolnik, 2010).

Entretanto, frequentemente os conjuntos habitacionais destinados à HIS são construídos em áreas não delimitadas como ZEIS e, mesmo quando são construídos em ZEIS, muitos estão alocados em áreas periféricas e desarticuladas da malha urbana. Isso ocorre em função da flexibilização nos padrões urbanísticos e de desempenho ambiental, em que as ZEIS são utilizadas como instrumento "[...] para segregar a população de baixa renda para áreas periféricas com baixa aptidão à urbanização, seja por fragilidade ambiental, seja por carência de infraestrutura" (Braga, 2016, p. 467). Logo, embora seja importante demarcar ZEIS de modo a assegurar a "[...] destinação de terras bem localizadas e com infraestrutura para os mais pobres" (Rolnik, 2010, p. 43), reiteradamente elas são delimitadas em áreas inadequadas tanto urbanística quanto ambientalmente (Braga, 2016). Tal circunstância também demonstra a ausência de parâmetros e diretrizes específicos para a criação de ZEIS (Braga, 2016), de modo a auxiliar na adequada alocação de HIS (Siqueira-Gay et al., 2019) e garantir uma melhor inserção urbana das mesmas.

A constatação desses processos tem levado a questionamentos sobre o grau de inserção urbana de empreendimentos voltados à HIS e a sua relação com o entorno imediato, além de fomentar reflexões teóricas e análises empíricas sobre a interferência, no espaço urbano, de programas de produção habitacional, como o MCMV, com ênfase na relação dos aspectos urbanísticos entre o empreendimento e a cidade, e suas repercussões para a segregação socioespacial de populações de menor renda.

A proposta deste estudo incorpora, na análise da inserção urbana dos conjuntos produzidos pelo PMCMV, um olhar ambiental à discussão habitacional. Assim, buscou-se compreender como o atendimento às demandas sociais de habitação dialoga com a proteção ambiental do meio natural. Objetivou-se, portanto, fazer uma análise da vinculação entre os efeitos ambientais e socioespaciais da implantação de empreendimentos do PMCMV - Faixa 1, em uma cidade média do interior paulista. 0 intuito foi contribuir para discussões acerca dos processos de provisão habitacional a partir de uma perspectiva ambiental, relacionando condicionantes do meio físico às estratégias de produção de cidade.

\section{Metodologia}

Tendo como recorte territorial o município de São Carlos-SP, a pesquisa foi pautada por levantamentos e análises bibliográficas e documentais. Foram verificadas as alterações da regulação urbanística local, sobretudo aquelas relacionadas à ampliação do perímetro urbano, as alterações de zoneamento e as flexibilizações dos parâmetros de uso e ocupação do solo, relacionando-as às problemáticas ambientais decorrentes dos processos de produção da cidade.

A integração e a sobreposição espacial de dados secundários em um Sistema de Informações Geográficas - SIG (QGIS, versão 3.4.7 'Madeira') foram necessárias para o mapeamento e a espacialização da distribuição dos empreendimentos do PMCMV - Faixa 1, na área de estudo. A localização das ZEIS também foi incorporada às análises espaciais, de modo a averiguar se a implantação dos empreendimentos seguiu a estratégia municipal de desenvolvimento urbano e de habitação de interesse social definida no Plano Diretor.

São Carlos é um município de porte médio, localizado no interior do estado de São Paulo, distante cerca de $230 \mathrm{~km}$ da capital paulista. Possui um elevado grau de urbanização (96\%), 1.137,30 km² de área (cerca de 6\% do território urbanizado), população estimada em 251.983 habitantes para 2019 e densidade demográfica de 195,15 hab./km² (São Carlos, 2010b; IBGE, 2020; SEADE, 2019).

Situado entre duas grandes bacias hidrográficas do estado de São Paulo, Tietê-Jacaré e Mogi-Guaçu, o município possui densa e significativa rede hídrica, composta por diversos córregos e nascentes. A maior parte do território são-carlense (58\%) está inserida sobre área de afloramento do Aquífero Guarani 
(Bertini et al., 2015), estabelecido na "[...] província geomorfológica das Cuestas Basálticas" (Peres et al., 2019, p. 150), que se caracteriza por ter "[...] relevo escarpado e alinhado, com cortes abruptos e íngremes em sua parte frontal e declive suave em seu reverso" (São Paulo, 2008, p. 19). Quanto à pedologia, a maior parte da área urbana do município é constituída por solos do tipo Latossolos (Trevisan et al., 2018) e a vegetação - constantemente reduzida a fragmentos florestais - é “[...] composta por florestas semidecídua e ripariana, o cerradão e o cerrado" (Costa et al., 2012, p. 145).

A regulamentação do Plano Diretor do município ocorreu pela Lei no 13.691/2005, com previsão de diversos instrumentos do Estatuto da Cidade (São Carlos, 2005, art. 13, inciso III). Entre 2009 e 2010, iniciou-se a elaboração do Plano Local de Habitação de Interesse Social - PLHIS da cidade, no mesmo período de adesão ao PMCMV. 0 atualmente vigente Plano Diretor Estratégico foi aprovado por meio da Lei no 18.053/2016 (São Carlos, 2016).

No Plano Diretor de 2005, foram delimitadas 14 Zonas Especiais de Interesse Social - ZEIS (São Carlos, 2005, arts. 75-77), sob três modalidades:

- ZEIS 1 - ocupadas por população de baixa renda, abrangendo ocupações espontâneas e loteamentos irregulares ou clandestinos, carentes de infraestrutura urbana e social, nos quais se pretende a implementação de programas habitacionais;

- ZEIS 2 - compostas por empreendimentos de iniciativa pública ou órgão institucional, já constituídos ou em implantação, destinados às habitações de interesse social, dotados de infraestrutura e de serviços urbanos ou que estejam recebendo investimentos dessa natureza;

- ZEIS 3 - compostas por imóveis não utilizados, não edificados ou subutilizados, preferencialmente dotados de infraestrutura e de serviços urbanos ou que estejam recebendo investimentos dessa natureza, adequados à implantação de programas habitacionais de interesse social.

\section{Resultados}

Foram construídos cinco conjuntos habitacionais do PMCMV - Faixa 1 em São Carlos-SP, cujas denominações constam na Tabela 1 (CEF, 2018). Todas as unidades contratadas são do tipo unifamiliar (casas térreas).

Tabela 1 - Caracterização dos empreendimentos habitacionais MCMV - Faixa 1 de São Carlos-SP

\begin{tabular}{cccc}
\hline Data contratação & Empreendimento & Unidades & Valor (R\$) \\
\hline $26 / 02 / 2010$ & Residencial Jardim Gramado - módulo I & 500 & 21.207 .709 \\
$26 / 02 / 2010$ & Residencial Jardim Gramado - módulo II & 250 & 10.604 .998 \\
$26 / 02 / 2010$ & Residencial Jardim Gramado - módulo III & 250 & 10.655 .772 \\
$24 / 12 / 2012$ & Residencial Eduardo Abdelnur & 986 & 69.019 .559 \\
$27 / 12 / 2012$ & Conjunto Habitacional Planalto Verde & 806 & 56.420 .000 \\
\hline
\end{tabular}

Fonte: Elaborado com base em dados da CEF (2018).

A adesão ao PMCMV coincide com o histórico de programas de habitação baseados predominantemente na provisão de novas habitações ou lotes urbanizados no município (Pulhez, 2012), em detrimento de alternativas como locação social e produção autogerida. Esta também é a realidade da maioria dos municípios brasileiros (61,1\%), que adotaram a construção de unidades habitacionais privadas como principal estratégia de ação relacionada à moradia, conforme dados da Pesquisa de Informações Básicas Municipais - Munic 2017 (IBGE, 2017). Assim, embora contrastante com a realidade nacional, em que o déficit habitacional é majoritariamente qualitativo, e não quantitativo (Libertun de Duren, 2018), “[...] a promoção pública da casa própria tem prevalecido sobre outras alternativas no conjunto de políticas habitacionais dos governos brasileiros" (Valença, 2014, p. 8).

A permanência de vazios urbanos especulativos também destoa da opção pela produção de novas unidades habitacionais. Considerando a possibilidade de demarcação de ZEIS em vazios urbanos, cabe 
ressaltar o grau de ociosidade de $20 \%$ do total da área urbana passível de ocupação em São Carlos-SP, constatado durante o levantamento de dados para elaboração do Plano Diretor de 2005. Na época, foram identificados 1.340 hectares de vazios urbanos, sendo 790 hectares de glebas e 550 hectares de lotes, dotados de infraestrutura, mas desocupados (São Carlos, 2019). Esses valores, apesar de expressivos, são inferiores aos resultados trazidos por Barbosa et al. (2018), que identificaram um percentual de $23 \%$ da área urbana composta por vazios urbanos em 2004, sendo 676,83 hectares de lotes parcelados (8\%) e 1.176,50 hectares de glebas (15\%), totalizando 1.853 hectares.

Esses dados sobre ociosidade se coadunam ao crescimento da mancha urbana superior ao incremento populacional $^{3}$ - que ocorreu em 1980 e tornou-se contínuo a partir de 1996 -, com consequente redução da densidade (Tabela 2). Por conseguinte, São Carlos-SP vem apresentando uma queda relativa em seu crescimento populacional, que contrasta com a expansão de sua área urbanizada (Figura 1), indicando que o crescimento urbano não tem sido determinado apenas pelas necessidades de acomodar seus habitantes.

Tabela 2 - Caracterização da urbanização de São Carlos-SP

\begin{tabular}{cccc}
\hline Ano & Área $\left(\mathbf{k m}^{2}\right)$ & População (hab.) & Densidade $\left(\mathbf{h a b} . \mathbf{k m m}^{2}\right)$ \\
\hline 1962 & 18,04 & 66.312 & $3.675,8$ \\
1972 & 23,07 & 91.214 & $3.953,8$ \\
1980 & 36,45 & 119.535 & $3.279,4$ \\
1986 & 38,45 & 139.162 & $3.619,3$ \\
1990 & 38,90 & 153.762 & $3.952,8$ \\
1996 & 54,20 & 177.222 & $3.269,8$ \\
2000 & 60,01 & 192.998 & $3.216,1$ \\
2006 & 73,95 & 216.266 & $2.924,5$ \\
2010 & 80,82 & 221.950 & $2.746,2$ \\
2015 & 102,70 & 241.389 & $2.350,4$ \\
\hline
\end{tabular}

Fonte: Adaptado de Costa et al. (2013, p. 74); Stanganini \& Lollo (2018, p. 122); IBGE (2019).

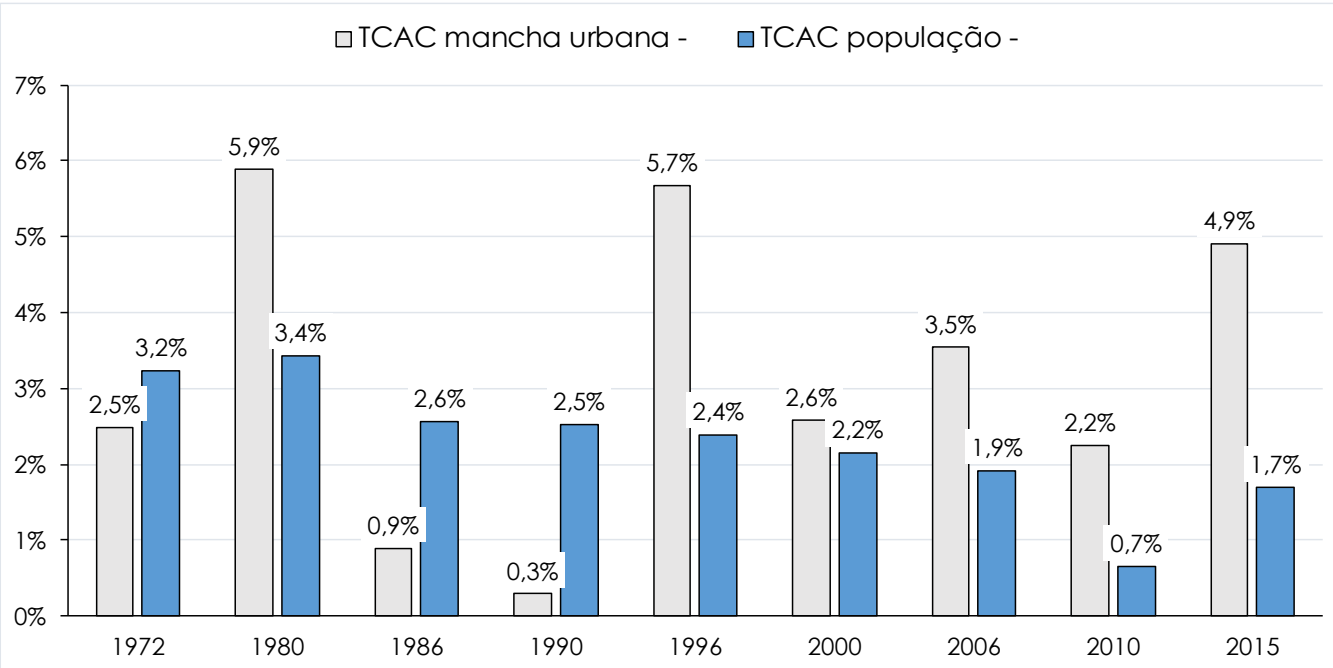

Figura 1 - Taxa de Crescimento Anual Composta (TCAC) em São Carlos-SP. Fonte: Elaborado com base em Costa et al. (2013, p. 74); Stanganini \& Lollo (2018, p. 122); IBGE (2019).

Há 30 anos, os vazios urbanos já eram indicados para ocupação preferencial (Aguiar, 1989). Ainda assim, apenas três ZEIS foram delimitadas em vazios urbanos no Plano Diretor de 2005, totalizando aproximadamente 11 hectares (Tabela 3). Essa situação é condizente com a realidade brasileira, de reduzida criação de ZEIS, tanto em vazios urbanos quanto em áreas voltadas à regularização fundiária (Soares et al., 2012; Braga, 2016).

\footnotetext{
3 “Um crescimento urbano espraiado seria aquele em que há um aumento da área urbanizada maior que o aumento da população, indicando um uso não eficiente da infraestrutura urbana” (Pereira et al., 2019, p. 18).
} 
Tabela 3 - Caracterização das ZEIS demarcadas no Plano Diretor de São Carlos-SP

\begin{tabular}{cccc}
\hline Tipo & Quantidade & Área (ha) & \% \\
\hline ZEIS 1 & 7 & 22,496 & 21,2 \\
ZEIS 2 & 4 & 72,682 & 68,4 \\
ZEIS 3 & 3 & 11,039 & 10,4 \\
Total & 14 & 106,217 & 100 \\
\hline
\end{tabular}

Fonte: Elaborado com base em dados de São Carlos (2005).

A subutilização de espaços vazios acarreta a "[...] necessidade de expandir os limites do perímetro urbano atual, o que induz a ocupação de novas áreas que, muitas vezes, são [de] mananciais" (Costa et al., 2012, p. 154). Nessa vertente, os conjuntos habitacionais do PMCMV - Faixa 1 foram implantados na Zona de Recuperação e Ocupação Controlada - Zona 3A. Essa zona, apesar de possuir diretriz para instituição de ZEIS (São Carlos, 2005, art. 33, inciso V), apresenta características, como: solo suscetível à erosões com córregos assoreados; infraestrutura precária; parcelamentos irregulares localizados nas proximidades de encostas de alta declividade e em áreas isoladas com precariedade de interligação viária com a malha urbana consolidada, e concentração da população de baixa renda (São Carlos, 2005, art. 32).

Com base nas supramencionadas características da Zona 3A, é razoável relacionar fragilidade com "[...] sinônimo de negligência governamental sistemática em relação à segurança ambiental [...]”, conforme afirmado por Davis (2006, p. 131). Por conseguinte, a implantação dos empreendimentos do PMCMV - Faixa 1, nesse caso, retrata a "[...] permissividade de ocupação de áreas com grandes fragilidades socioambientais", apontada por Peres \& Silva (2013, p. 21), ao abordarem aspectos ambientais do Plano Diretor de 2005.

Diversos autores (Costa et al., 2013, 2019; Mazzuco et al., 2018) também demonstraram que a região em que a Zona $3 \mathrm{~A}$ se insere apresenta maior vulnerabilidade à poluição das águas subterrâneas, devido aos altos coeficientes de permeabilidade em função da composição arenosa e porosa. Costa et al. (2012) constataram que a Zona $3 \mathrm{~A}$ possuía $15,7 \mathrm{~km}^{2}$ de área, sendo que $38,2 \%$ já estavam urbanizados e somente $26,8 \%\left(4,2 \mathrm{~km}^{2}\right)$ estavam disponíveis para uso urbano. Esta limitação ocorre porque $35 \%$ eram áreas impróprias à urbanização, sendo: APPs de margens de rios e de nascentes; áreas com declividade superior a 30\%; áreas compostas por fragmentos florestais, e áreas constituídas pela Formação Botucatu, integrantes do sistema de recarga do Aquífero Guarani (Costa et al., 2012).

0 incremento na ocupação de áreas ambientalmente frágeis relaciona-se diretamente à forma de urbanização do território são-carlense. Nessa localidade, a apropriação do espaço natural pelo ambiente construído se deu pela ocupação dos fundos de vale e pela implantação de avenidas marginais, "[...] em detrimento da preservação de nascentes e córregos que foram sendo suprimidos, confinados ou canalizados segundo demandas da expansão urbana" (São Carlos, 2011, p. 44).

Esse processo de urbanização se coaduna às tendências na legislação de regulação urbanística, pois, desde a década de 1990, a legislação urbana federal direciona o desenvolvimento urbano às custas da qualidade ambiental. Isso tem ocorrido tanto em função do "[...] rebaixamento dos padrões urbanísticos dos loteamentos em áreas declaradas de interesse social - vide Lei n. 9.785 (Brasil, 1999)" quanto pela "[...] permissão da regularização de interesse social em APP, por meio da Lei n. 11.977 (Brasil, 2009)" (Freitas, 2014, p. 113). A opção por esse modelo de provisão de HIS tem demonstrado que "[...] questões de natureza estrutural, como o desequilíbrio entre os direitos coletivos - à moradia e à qualidade ambiental urbana - e o direito de propriedade, permanecem intocadas" (Freitas, 2014, p. 114).

Nessa perspectiva, as alterações na legislação, necessárias à viabilidade de conjuntos habitacionais para HIS, também ocorreram na implantação dos empreendimentos do PMCMV. Conforme Rufino (2015), foi essencial que houvesse tais alterações para conversão de zona rural em zona urbana. Esse processo estaria "[...] articulado em diversos casos à delimitação de ZEIS, que permitiram em muitas situações a flexibilização de parâmetros de uso, ocupação e parcelamento do solo", possibilitando "[...] maior adensamento e ou adequação à implantação de grandes empreendimentos do Programa, seja na forma de loteamento ou condomínio". Em São Carlos-SP, o Residencial Eduardo Abdelnur ilustra tal situação. 
Como na Lei no 14.986 (São Carlos, 2009), ficou definido que seriam enquadrados como Empreendimentos Habitacionais de Interesse Social - EHIS tanto os empreendimentos implantados em ZEIS quanto os destinados às famílias com renda mensal de até três salários mínimos (s.m.), o Residencial Eduardo Abdelnur e os demais conjuntos habitacionais do PMCMV - Faixa 1 do município foram incluídos dentre os EHIS. Essa legislação, articulada ao artigo 137 do Plano Diretor (São Carlos, 2005), que previa que os EHIS poderiam ser executados tanto em ZEIS quanto em empreendimentos particulares aprovados por Lei, garantiu que, além de os produtos do PMCMV serem considerados EHIS, estes não necessariamente precisariam ser construídos em ZEIS. Isso beneficiou duplamente os loteadores.

A classificação como EHIS permite que sejam construídos ou delimitados lotes de, no mínimo, $150 \mathrm{~m}^{2}$ (São Carlos, 2005, art. 138, inciso I). No caso do mencionado Residencial Eduardo Abdelnur, os loteadores se beneficiaram da terra rural mais barata, pois tal empreendimento foi construído na Zona de Uso Predominantemente Agrícola - Zona 7, que possuía como diretriz "[...] impedir a implantação de usos urbanos que impliquem em adensamento populacional e construtivo, promovendo, preferencialmente, os usos agrícolas" (São Carlos, 2005, art. 54, inc. II). Foram viabilizados, desta forma, padrões habitacionais menos restritivos (lotes menores), em um processo de adensamento de territórios periféricos, isentos de equipamentos e serviços públicos, e desprovidos de infraestrutura.

Como expõe Camargo (2019, p. 135), “[...] ao urbanizar áreas rurais, a expansão indiscriminada da cidade compromete as reservas de água potável e a produção de alimentos, através da extinção dos núcleos de agricultura familiar". Ademais, com a precariedade urbanística, a responsabilidade pela instalação e manutenção de infraestrutura e equipamentos públicos é transferida ao Estado.

Logo, similar ao identificado em Uberaba-MG (Soares et al., 2013), nenhum dos conjuntos habitacionais do PMCMV - Faixa 1 foi instaurado nas zonas instituídas pela legislação urbanística para HIS em São Carlos-SP. Isso já era esperado, pois o Plano Diretor de 2005 possibilitava a criação de novas ZEIS (1, 2 ou 3), sendo que os proprietários de áreas passíveis de delimitação poderiam realizar solicitação para tanto, desde que as áreas fossem destinadas para ZEIS 3 (São Carlos, 2005, art. 78 e 79, inciso V). Consequentemente, embora o PLHIS tenha evidenciado a necessidade de "[...] rompimento da lógica de periferização urbana e a urgência pela implantação de empreendimentos de Habitação de Interesse Social em áreas centrais dotadas de infraestrutura" (Peres, 2012, p. 309-310), a localização dos empreendimentos Faixa 1 não necessariamente acompanhou a "[...] demarcação de áreas de interesse social estabelecidas nos PLHIS ou Planos Diretores, mas sim, a disponibilidade e aquisição de terrenos adquiridos pelas empresas construtoras antes ou após o início do PMCMV" (Lopes \& Shimbo, 2015, p. 241). Estes compuseram a periferia ampliada, abrindo "[...] novas fronteiras de expansão urbana e especulação imobiliária" (Lopes \& Shimbo, 2015, p. 252).

Os empreendimentos aprovados no extremo sul e sudoeste da cidade, embora mais lucrativos para os loteadores, encarecem os custos de manutenção para o poder público, com o reparo de infraestruturas. Ademais, por serem loteamentos de grandes densidades, construídos em área de recarga do Aquífero Guarani, em solos colapsáveis, de textura arenosa, e caracterizados por alta permeabilidade e maior propensão à erosão, estes podem levar ao comprometimento da qualidade da água subterrânea pela contaminação do lençol freático e desencadear processos erosivos, além do fato de a impermeabilização poder reduzir a capacidade de recarga do aquífero (Pulhez, 2012; Schenk et al., 2015; Lopes \& Shimbo, 2015; Fantin et al., 2017).

Cabe ressaltar, no entanto, que tais conjuntos habitacionais foram alocados próximos das ZEIS de vazios, demarcadas de modo concentrado na região sul da cidade. Isso, a despeito de um conjunto de outras glebas vazias mais bem localizadas, como as identificadas por Barbosa $(2018)^{4}$, conforme

\footnotetext{
${ }^{4}$ Embora algumas tenham sido parceladas, essas glebas identificadas por Barbosa (2018) permanecem desocupadas em sua maioria, sendo caracterizadas por possuírem área maior ou igual a $10.000 \mathrm{~m}^{2}$ (1ha) e estarem localizadas dentro dos limites do perímetro urbano de 2005 .
} 
Figura $2^{5}$. Essa concentração de ZEIS de vazios em uma mesma região, com diversas vulnerabilidades socioambientais identificadas, se relaciona à estratégia de valorização de terras periféricas para viabilização de determinados empreendimentos, com o uso deste instrumento urbanístico "[...] para legitimar uma determinada distribuição da população no território" (Camargo, 2019, p. 127), visto a constatada homogeneidade social da região.

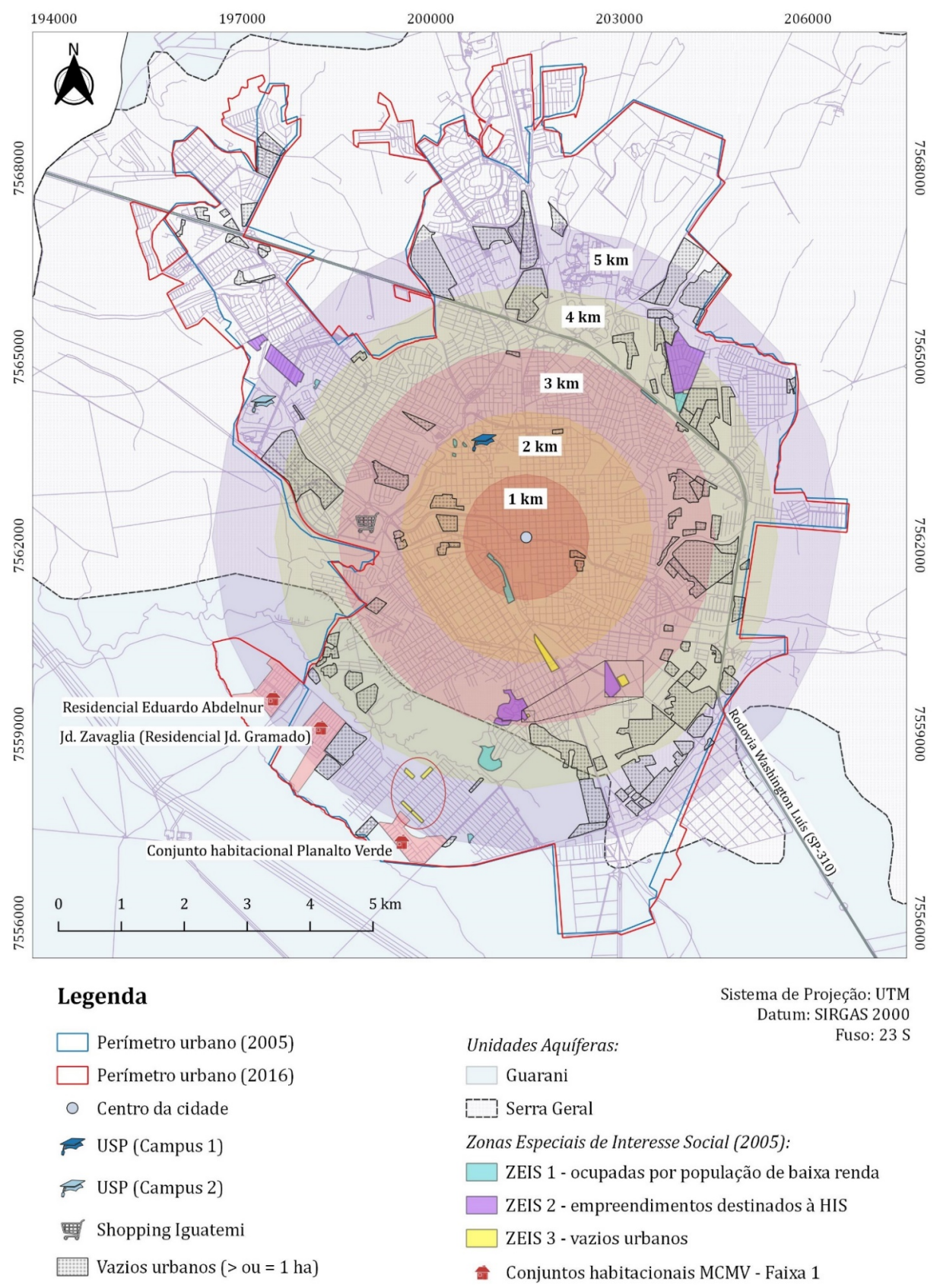

Figura 2 - Distribuição das ZEIS, dos empreendimentos MCMV - Faixa 1 e dos vazios urbanos com área maior ou igual a 1 ha em São Carlos-SP. Fonte: Elaborado com base em DataGEO (2007); IBGE (2015); São Carlos $(2005,2016)$; e Barbosa (2018, p. 152).

\footnotetext{
${ }^{5}$ Construídos lado a lado, os três módulos do Residencial Jardim Gramado foram representados de modo agregado, com o nome instituído pela Lei n ${ }^{\circ}$ 15.329/2010 (São Carlos, 2010a). Os quatro polígonos no interior do círculo vermelho referem-se a uma mesma ZEIS. Devido à escala do mapa, uma das ZEIS foi representada com zoom, de modo a facilitar a visualização.
} 


\section{Discussão}

A influência dos setores imobiliários e da construção civil pautou as políticas públicas recentes voltadas à moradia. A precariedade locacional é característica de muitos conjuntos residenciais construídos (Ribeiro et al., 2016), devido à priorização do mercado privado de habitação pelo governo federal. Essa realidade se atrela à falta de "[...] interesse ou capacidade institucional e reguladora" das prefeituras para limitar a interferência do setor privado na escolha da localização dos empreendimentos (Jesus \& Denaldi, 2018, p. 83).

Ademais, tem-se um evidente alinhamento entre poder público e setor privado, com vantagens para ambos, relacionadas à expressiva quantidade de unidades entregues pela construção de grandes conjuntos habitacionais. Como visto no estudo de caso, raramente as ZEIS de vazios urbanos são do mesmo tamanho dos terrenos em que são construídos os conjuntos habitacionais produzidos. Nessas circunstâncias, o loteador recorre a terrenos rurais e/ou periféricos, diminuindo os custos por unidade em função dos ganhos de escala ${ }^{6}$ e da padronização construtiva ${ }^{7}$ (Shimbo, 2016; Libertun de Duren, 2018), sendo que a prefeitura também estaria interessada "[...] no menor preço de terra disponível na cidade para maximizar o número de unidades produzidas" (Biderman et al., 2019, p. 126).

Em tal conjuntura, são notórios os casos em que a prefeitura municipal cede aos interesses dominantes de construtoras e desconsidera as ZEIS na alocação dos empreendimentos habitacionais, desarticulando política urbana e habitacional, no intuito de agilizar o processo de provisão de moradias (Soares et al., 2013). Nesse contexto, também é aceita a aprovação de HIS em áreas ambientalmente inadequadas. No estudo de caso analisado, esse processo é anterior à adesão ao PMCMV, mas intensificou-se após tal aderência, revelando uma "[...] enorme dificuldade de viabilização política na produção de assentamentos financeiramente acessíveis em espaços propícios, no ponto de vista do quadro natural" (Freitas, 2014, p. 122).

Tal situação coincide com o "[...] modelo de ocupação urbana implementado ao longo dos anos em São Carlos, [que] desconsiderou as características físicas e ambientais" (Schenk \& Peres, 2014, p. 3) do território, e demonstra a inalterada atuação das leis de mercado. Este quadro se estabelece de tal maneira que condicionantes do ambiente natural acabam por desvalorizar determinadas áreas, tornando-as inadequadas à urbanização para populações com maior poder aquisitivo e, consequentemente, oportunidade de moradia de baixo custo (Davis, 2006), tanto para ocupações informais quanto para a destinação de HIS. Nessa linha, no contexto são-carlense e em outras municipalidades, a produção de loteamentos para a população de baixa renda "[...] tornou-se um investimento lucrativo, desde que realizado de forma precária em terras baratas" (Schenk \& Peres, 2014, p. 6).

Em suma, o PMCMV não funcionou como uma política habitacional e urbana, mas sim como uma linha de financiamento (Ferreira, 2014). Por meio deste, "[...] o governo pretendia direcionar [...] o deslocamento de atuação do mercado imobiliário para as faixas de renda mais baixas", via "[...] produção por 'oferta', e não por demanda" (Camargo, 2019, p. 125). Como consequência, foram reforçadas práticas amplamente disseminadas, como a ocupação de áreas ambientalmente inadequadas por população de baixa renda via HIS. Nota-se, portanto, uma evidente necessidade de "[...] articular a lógica do financiamento habitacional às estratégias de planejamento e desenvolvimento urbano", não podendo ficar a cargo unicamente do município a tarefa de "[...] tratar os conflitos e disputas territoriais históricas em torno da reprodução do espaço urbano" (Jesus \& Denaldi, 2018, p. 83).

Por esse ângulo, cabe aludir à experiência da primeira versão do Programa de Arrendamento Residencial - PAR, que determinava que áreas beneficiadas pelo programa deveriam contar com infraestruturas básicas, havendo limitação de tamanho dos empreendimentos. Exigências estas que

\footnotetext{
${ }^{6}$ A escala estaria relacionada à "otimização do tempo processual junto aos órgãos municipais e estaduais de aprovação e licenciamento dos projetos, ou a otimização de diversas atividades relacionadas ao canteiro de obra (logística de materiais, deslocamento de maquinário) [...]" (Camargo, 2019, p. 128).

7 "A padronização das tipologias habitacionais produzidas tem estreita relação com a padronização do processo de produção, que envolve desde a uniformização das medidas, materiais e componentes, até as formas de execução e gestão no canteiro” (Camargo, 2019, p. 127).
} 
resultaram no preenchimento de vazios urbanos, favoreceram a construção de conjuntos habitacionais menores, em áreas urbanas consolidadas, evitando-se regiões periféricas e distantes de núcleos urbanizados, além de forçar governos locais a se esforçarem em prover infraestruturas antes de qualquer investimento realizado pelo governo federal (Valença \& Bonates, 2010; Valença, 2014), em contraposição ao recorrente modelo de "urbanização incompleta" (Santoro, 2014, p. 173).

A experiência do PAR se notabiliza perante a existência de glebas, lotes parcelados e imóveis subutilizados e sem uso (vacância habitacional) para fins especulativos nas cidades brasileiras, o que leva à ociosidade das infraestruturas em áreas consolidadas e contrapõe-se ao déficit habitacional existente. 0 combate a esses vazios urbanos, no entanto, dificilmente se concretiza. No PMCMV, por exemplo, apesar da ampliação das possibilidades de financiamento para a produção de HIS (Jesus \& Denaldi, 2018), não houve a implementação de "[...] mecanismos de controle do processo de valorização imobiliária de fundo especulativo" (Freitas \& Frota, 2015, p. 24).

Nesse sentido, a despeito da importância de políticas preventivas para evitar os "[...] potenciais impactos ambientais do modelo excludente de produção da cidade", os avanços legais e institucionais para a regularização fundiária são mais evidentes do que para a aplicação dos instrumentos voltados a evitar a retenção especulativa - como as ZEIS de vazio e o IPTU Progressivo, previstos no Estatuto da Cidade (Freitas, 2014, p. 113). A efetivação de tais "[...] mecanismos de combate ao modelo excludente de produção da cidade" teria o efeito de aumentar a oferta de terra urbanizada e facilitar o acesso à cidade pela população de baixa renda, além de "[...] atender ao direito à moradia em áreas propícias ao desenvolvimento urbano, reduzindo a pressão por ocupações precárias em áreas ambientalmente frágeis" (Freitas, 2014, p. 114).

É pertinente destacar, portanto, a manifesta dificuldade em aplicar tais instrumentos urbanísticos (Santos \& Montandon, 2011), em virtude dos impasses de regulamentação e efetivação dos mesmos (Pulhez, 2012). Embora tenha havido uma "[...] expressiva incorporação formal [...], boa parte não tem sido implantada ou não foi regulamentada, ensejando um cenário em que ainda não são autoaplicáveis" (Goulart et al., 2013, p. 197). Foram poucos os planos diretores que "[...] instituíram instrumentos voltados para a ocupação dos vazios urbanos infraestruturados em áreas centrais por parte da população de baixa renda, como as ZEIS em áreas vazias" (Santos \& Montandon, 2011, p. 276).

A falta de aplicação dos instrumentos jurídico-urbanísticos capazes de garantir o cumprimento da função social da propriedade relaciona-se com os interesses contraditórios existentes, relativos à “[...] permanência da expansão urbana como estratégia do mercado imobiliário" (Santoro, 2014, p. 181) pela "[...] lógica de (re)produção do espaço urbano", que reduzem os instrumentos e os planos urbanos setoriais à "mera retórica" (Pulhez, 2012, p. 115). Desta forma, "[...] a explicação do desempenho das políticas urbanas está mais em variáveis de caráter político, ou mesmo cultural, e não econômicas e urbanísticas" (Braga, 2011, p. 21).

Esta realidade se justificaria pela "implementação discriminatória" dos planos diretores, isto é, "[...] aquilo que contraria os interesses dominantes, em especial relacionados com o rentismo fundiário e com o mercado imobiliário, não é implementado" (Maricato et al., 2018, p. 207). Logo, apenas a elaboração de Planos Diretores não implica, necessariamente, na condução do ordenamento urbano pautado pelos instrumentos urbanísticos do Estatuto da Cidade (Braga, 2011), mesmo quando estes instrumentos estão previstos nos planos diretores municipais, e até mesmo quando são regulados posteriormente por leis complementares (Ondetti, 2016). Isto ocorre porque "[...] o plano diretor não é uma peça puramente científica e técnica, mas uma peça política” (Villaça, 2004, p. 237), cuja efetividade é condicionada por disputas políticas e assimetrias de poder, e pelo nível de envolvimento da sociedade nas discussões durante sua elaboração, implementação e monitoramento. 


\section{Considerações finais}

A análise da vinculação entre os efeitos ambientais e socioespaciais da implantação de empreendimentos com recursos do PMCMV - Faixa 1 salientou a relação intrínseca entre questão ambiental urbana e provisão habitacional. Por meio de um estudo de caso, identificou-se a intensificação na ocupação de áreas ambientalmente impróprias à urbanização pela provisão habitacional via financiamento público. Essa conjuntura revela uma desarticulação entre funções social e ambiental, bem como entre políticas urbanas e habitacionais, visto a expansão horizontal desproporcional ao incremento populacional. Tais resultados se deram em um contexto histórico de negligência das condições físicoambientais do território no processo de desenvolvimento urbano.

Ao preterir a regulamentação do uso da terra e o combate à especulação imobiliária em favor do financiamento de novas moradias, políticas públicas como o PMCMV contribuíram para o agravamento de problemas socioambientais urbanos, como a segregação socioespacial e a ocupação de áreas ambientalmente inadequadas à urbanização. Nesse sentido, enquanto continuar sendo economicamente atrativo manter vazios urbanos, áreas menos valorizadas devido a restrições ambientais serão alvo tanto das ocupações irregulares por populações de baixa renda quanto da construção de conjuntos habitacionais voltados à HIS.

Seria oportuno avaliar, em estudos futuros, se a replicação de tais problemáticas também ocorreu em municípios com práticas mais alinhadas aos preceitos da sustentabilidade urbana. Tal avaliação poderia verificar diferentes repercussões das formas de operacionalização de uma política pública de provisão habitacional que, ao ser colocada em prática, não estimulou o aproveitamento de espaços ociosos.

\section{Agradecimentos}

O presente trabalho foi realizado com apoio da Coordenação de Aperfeiçoamento de Pessoal de Nível Superior - Brasil (CAPES) - Código de Financiamento 001.

\section{Referências}

Aguiar, R. L. (1989). Mapeamento geotécnico da área de expansão urbana de São Carlos-SP: contribuições ao planejamento (Dissertação de mestrado). Escola de Engenharia de São Carlos, Universidade de São Paulo, São Carlos.

Barbosa, Y. B. (2018). Análise temporal do processo de ocupação dos vazios urbanos no município de São Carlos, SP: sob a ótica de uma cidade compacta (Tese de doutorado). Universidade Federal de São Carlos, São Carlos.

Barbosa, Y. B., Gonçalves, L. M., \& Lollo, J. A. (2018). A dinâmica espacial dos vazios urbanos nos marcos temporais de 2004 e 2014 em subsídio ao Plano Diretor de São Carlos-SP. In Anais do 8º Congresso Luso-Brasileiro para o Planeamento Urbano, Regional, Integrado e Sustentável. Coimbra, Portugal: Universidade do Minho.

Bertini, M. A., Fushita, A. T., \& Lima, M. I. S. (2015). Vegetation coverage in hydrographic basins in the central region of the State of São Paulo, Brazil. Brazilian Journal of Biology = Revista Brasileira de Biologia, 75(3), $709-717$. http://dx.doi.org/10.1590/1519-6984.21713.

Biderman, C., Acosta, C., Ramos, F., Hiromoto, M., Terentim, G., Caldeira, J., \& Pacheco, T. (2019). Morar longe: o Programa Minha Casa Minha Vida e a expansão das regiões metropolitanas. São Paulo: Instituto Escolhas. Recuperado em 15 de fevereiro de 2019, de http://www.escolhas.org/wpcontent/uploads/2019/01/QCML_FINAL_REV_jan19v2_FINAL21JAN.pdf

Braga, R. (2011). Dinâmica regional e política urbana: uma análise das cidades de porte médio da Região Administrativa de Campinas/SP. G\&DR, 7(2), 3-24. 
Braga, R. (2016). Indicadores de sustentabilidade para avaliação de zonas especiais de interesse social (ZEIS) para implantação de habitação de interesse social na cidade de Piracicaba-SP. Caderno de Geografia, 26(46), 464-485. http://dx.doi.org/10.5752/P.2318-2962.2016v26n46p464.

Brasil. (2001, 17 de julho). Lei no 10.257, de 10 de julho de 2001. Regulamenta os arts. 182 e 183 da Constituição Federal, estabelece diretrizes gerais da política urbana e dá outras providências. Brasília: Diário Oficial da União.

Brasil. (2009a, 7 de julho). Lei no 11.977, de 7 de julho de 2009. Dispõe sobre o Programa Minha Casa, Minha Vida PMCMV e a regularização fundiária de assentamentos localizados em áreas urbanas; altera o Decreto-Lei $n^{\circ}$ 3.365, de 21 de junho de 1941, as Leis no 4.380, de 21 de agosto de 1964, 6.015, de 31 de dezembro de 1973, 8.036, de 11 de maio de 1990, e 10.257, de 10 de julho de 2001, e a Medida Provisória no 2.197-43, de 24 de agosto de 2001; e dá outras providências. Brasília: Diário Oficial da União.

Brasil. Secretaria Nacional de Habitação - SNH. (2009b). Guia para regulamentação e implementação de Zonas Especiais de Interesse Social - ZEIS em Vazios Urbanos. Brasília: Ministério das Cidades.

Caixa Econômica Federal - CEF. (2018). Minha Casa Minha Vida Urbana: empreendimentos Minha Casa Minha Vida: empreendimentos faixa 1 MCMV - 31/03/2018. Recuperado em 10 de abril de 2019, de http://www.caixa.gov.br/voce/habitacao/minha-casa-minha-vida/urbana/Paginas/default.aspx

Camargo, C. M. (2019). Produção habitacional na Região Administrativa Central do estado de São Paulo: reconfigurações territoriais recentes.Terr@Plural,13(3), 122-140. https://doi.org/10.5212/TerraPlural.v.13i3.0010.

Costa, C. W., Dupas, F. A., \& Pons, N. A. (2012). Regulamentos de uso do solo e impactos ambientais: avaliação crítica do plano diretor participativo do município de São Carlos, SP. Geociências, 31(2), 143-157.

Costa, C. W., Lorandi, R., Lollo, J. A., \& Santos, V. S. (2019). Potential for aquifer contamination of anthropogenic activity in the recharge area of the Guarani Aquifer System, southeast of Brazil. Groundwater for Sustainable Development, 8, 10-23. http://dx.doi.org/10.1016/j.gsd.2018.08.007.

Costa, C., Dupas, F. A., Cespedes, J. G., \& Silva, L. F. (2013). Mapeamento da expansão urbana, cenários futuros de crescimento populacional e o consumo de recursos hídricos no município de São Carlos, SP. Geociências, 32(1), 6380.

Davis, M. (2006). Planeta Favela (Vol. 1). São Paulo: Boitempo.

Fantin, M., Schenk, L. B. M., \& Peres, R. B. (2017). Propostas de expansão urbana para o Plano Diretor de São Carlos (SP): um olhar sob o prisma das limitações dos meios físico e biótico. In A. Perez Fo., \& R. R. Amorim (Eds.), Os desafios da Geografia Física na fronteira do conhecimento (pp. 6577-6590). Campinas: Instituto de Geociências, Universidade Estadual de Campinas. https://doi.org/10.20396/sbgfa.v1i2017.1853.

Ferreira, G. G., Calmon, P., Fernandes, A. S. A., \& Araújo, S. M. V. G. (2019). Política habitacional no Brasil: uma análise das coalizões de defesa do Sistema Nacional de Habitação de Interesse Social versus o Programa Minha Casa, Minha Vida. urbe. Revista Brasileira de Gestão Urbana, 11, e20180012. http://dx.doi.org/10.1590/21753369.011.001.ao04.

Ferreira, J. S. W. (2014). Minha Casa, Minha Vida: notas sobre a responsabilidade coletiva de um desastre urbano. Revista Contraste, 1, 110-119.

Ferreira, J. S. W., \& Motisuke, D. (2007). A efetividade da implementação de Zonas Especiais de Interesse Social no quadro habitacional brasileiro: uma avaliação inicial. In L. M. M. Bueno, \& R. Cymbalista (Eds.), Planos diretores municipais: novos conceitos de planejamento territorial (pp. 33-58.). São Paulo: Annablume.

Freitas, C. F. S. (2014). Ilegalidade e degradação em Fortaleza: os riscos do conflito entre a agenda urbana e ambiental brasileira. urbe. Revista Brasileira de Gestão Urbana, 6(1), 109-125.

http://dx.doi.org/10.7213/urbe.06.001.AC02.

Freitas, C., \& Frota, N. (2015). Política ambiental urbana no cenário de expansão do capital imobiliário: o caso da Maraponga em Fortaleza. E-metropolis, 21(6), 21-31. Recuperado em 10 de abril de 2019, de 
http://emetropolis.net/artigo/140?name=politica-ambiental-urbana-no-cenario-de-expansao-do-capitalimobiliario-o-caso-da-maraponga-em-fortaleza

Fundação Sistema Estadual de Análise de Dados - SEADE. (2019). Perfil dos municípios paulistas. Recuperado em 6 de junho de 2019, de http://www.perfil.seade.gov.br/

Gondim, L. M. P. (2012). Ambiente urbano e questão social: habitação popular em áreas de preservação ambiental. Caderno CRH, 25(64), 115-130. http://dx.doi.org/10.1590/S0103-49792012000100009.

Goulart, J. O., Terci, E. T., \& Otero, E. V. (2013). A dinâmica urbana de cidades médias do interior paulista sob o Estatuto da Cidade. Revista Brasileira de Estudos Urbanos e Regionais, 15(1), 183-200.

http://dx.doi.org/10.22296/2317-1529.2013v15n1p183.

Goulart, J. O., Terci, E. T., \& Otero, E. V. (2016). Segregação socioespacial e política urbana em cidades médias no Brasil contemporâneo (2001-2011). Caderno CRH, 29(78), 553-570. http://dx.doi.org/10.1590/s010349792016000300009.

Honda, S. C. A. L. (2013). Política habitacional de baixa renda e a atuação do capital privado: o Programa de Arrendamento Residencial em Presidente Prudente (SP). urbe. Revista Brasileira de Gestão Urbana, 5(1), $107-117$. http://dx.doi.org/10.7213/urbe.7788.

Instituto Brasileiro de Geografia e Estatística - IBGE. (2015). Mapas: bases e referenciais: bases cartográficas: malhas digitais: municipal 2015. Recuperado em 6 de junho de 2019, de https://mapas.ibge.gov.br/bases-ereferenciais/bases-cartograficas/malhas-digitais.html

Instituto Brasileiro de Geografia e Estatística - IBGE. (2017). Perfil dos municípios brasileiros 2017. Rio de Janeiro: IBGE.

Instituto Brasileiro de Geografia e Estatística - IBGE. (2019). Estimativas da população. Rio de Janeiro: IBGE. Recuperado em 3 de julho de 2019, de https://www.ibge.gov.br/estatisticas/sociais/populacao/9103estimativas-depopulacao.html?edicao $=17283 \& \mathrm{t}=$ downloads

Instituto Brasileiro de Geografia e Estatística - IBGE. (2020). IBGE cidades: São Carlos. Rio de Janeiro: IBGE. Recuperado em 28 de janeiro de 2020, de https://cidades.ibge.gov.br/brasil/sp/sao-carlos/panorama

Jesus, P., \& Denaldi, R. (2018). Experiências de regulação urbana e suas possibilidades: análise a partir do Programa Minha Casa Minha Vida na Região do Grande ABC (São Paulo). Revista Latinoamericana de Estudios Urbano Regionales, 44(132), 67-87. http://dx.doi.org/10.4067/s0250-71612018000200067.

Libertun de Duren, N. R. (2018). Why there? Developers' rationale for building social housing in the urban periphery in Latin America. Cities, 72, 411-420. http://dx.doi.org/10.1016/j.cities.2017.10.006.

Lopes, J. M. A., \& Shimbo, L. Z. (2015). Projeto e produção da habitação na região central do estado de São Paulo: condições e contradições do PMCMV. In C. S. Amore, L. Z. Shimbo, \& M. B. C. Rufino (Eds.), Minha Casa... e a cidade? Avaliação do Programa Minha Casa Minha Vida em seis estados brasileiros (1. ed., pp. 229-254). Rio de Janeiro: Letra Capital.

Maricato, E., Colosso, P., \& Comarú, F. A. (2018). Um projeto para as cidades brasileiras e o lugar da saúde pública. Saúde em Debate, 42(3), 199-211. http://dx.doi.org/10.1590/0103-11042018s315.

Mazzuco, G. G., Lioni, A. B., Trevisan, D. P., Lorandi, R., \& Moschini, L. E. (2018). Avaliação da efetividade das políticas públicas voltadas para a proteção das áreas de captação de água: estudo de caso no município de São Carlos-SP. Águas Subterrâneas, 32(1), 154-161. http://dx.doi.org/10.14295/ras.v32i1.28977.

Menzori, I. D., \& Falcoski, L. A. N. (2016). Estudo das Áreas Especiais de Interesse Social e Áreas de Preservação e Recuperação de Mananciais: o caso do Programa Minha Casa Minha Vida em Araraquara/SP. In Anais do 7o Congresso Luso-Brasileiro para o Planeamento Urbano, Regional, Integrado e Sustentável - PLURIS. Maceió: Viva Editora.

Ondetti, G. (2016). The social function of property, land rights and social welfare in Brazil. Land Use Policy, 50, 2937. http://dx.doi.org/10.1016/j.landusepol.2015.08.028. 
Pereira, R. H. M., Nadalin, V. G., Gonçalves, C. N., \& Nascimento, I. F. (2019). ODS 11: tornar as cidades e os assentamentos humanos inclusivos, seguros, resilientes e sustentáveis. Brasília: IPEA.

Peres, R. B. (2012). O planejamento regional e urbano e a questão ambiental: análise da relação entre o plano de bacia hidrográfica Tietê-Jacaré e os planos diretores municipais de Araraquara e São Carlos, SP (Tese de doutorado). Universidade Federal de São Carlos, São Carlos.

Peres, R. B., \& Silva, R. S. (2013). Interfaces da gestão ambiental urbana e gestão regional: análise da relação entre Planos Diretores Municipais e Planos de Bacia Hidrográfica. urbe. Revista Brasileira de Gestão Urbana, 5(2), 13-25. http://dx.doi.org/10.7213/urbe.05.002.SE01.

Peres, R. B., Silva, S. R. M., \& Schenk, L. B. M. (2019). Paisagem urbana, espaços públicos e a gestão territorial em cidades médias paulistas: reflexões a partir de São Carlos, SP, Brasil. Terr@Plural, 13(3), 141-164. https://doi.org/10.5212/TerraPlural.v.13i3.0011.

Pulhez, M. M. (2012). Plano de habitação, produção de habitação: as fronteiras de conflito da política pública considerações a partir de um estudo de caso em São Carlos (SP). Revista Brasileira de Estudos Urbanos e Regionais, 14(1), 99-117. http://dx.doi.org/10.22296/2317-1529.2012v14n1p99.

Ribeiro, S. C. L., Daniel, M. N., \& Abiko, A. (2016). ZEIS maps: comparing areas to be earmarked exclusively for social housing in São Paulo city. Land Use Policy, 58, 445-455.

http://dx.doi.org/10.1016/j.landusepol.2016.08.010.

Rolnik, R. (2010). Como produzir moradia bem localizada com recursos do Programa Minha Casa Minha Vida? Implementando os instrumentos do Estatuto da Cidade. Brasília: Ministério das Cidades.

Rufino, M. B. C. (2015). Um olhar sobre a produção do PMCMV a partir de eixos analíticos. In C. S. Amore, L. Z. Shimbro, \& M. B. C. Rufino (Eds.), Minha casa... e a cidade? Avaliação do programa minha casa minha vida em seis estados brasileiros (1. ed., pp. 51-72). Rio de Janeiro: Letra Capital.

Santoro, P. F. (2014). Perímetro urbano flexível, urbanização sob demanda e incompleta: o papel do Estado frente ao desafio do planejamento da expansão urbana. Revista Brasileira de Estudos Urbanos e Regionais, 16(1), $169-187$. http://dx.doi.org/10.22296/2317-1529.2014v16n1p169.

Santos, O. A., Jr., \& Montandon, D. T. (2011). Os planos diretores pós-estatuto da cidade: balanço crítico e perspectivas. Rio de Janeiro: Letra Capital/Observatório das Metrópoles, Instituto de Pesquisa e Planejamento Urbano e Regional, Universidade Federal do Rio de Janeiro.

São Carlos. Prefeitura Municipal. (2005, 25 de novembro). Lei no 13.691, de 25 de novembro de 2005. Institui o Plano Diretor do Município de São Carlos e dá outras providências. São Carlos: Diário Oficial do Município.

São Carlos. Prefeitura Municipal. (2009, 6 de julho). Lei $n^{\circ}$ 14.986, de 6 de julho de 2009. Dispõe sobre Empreendimentos Habitacionais de Interesse Social e sua vinculação ao "Programa Minha Casa Minha Vida", do Governo Federal, e dá outras providências. São Carlos: Diário Oficial do Município.

São Carlos. Câmara Municipal. (2010a, 17 de junho). Lei nº 15.329 de 17 de junho de 2010. Denomina de "Residencial Deputado José Zavaglia", o Residencial Jardim Gramado I, II e III. São Carlos: Diário Oficial do Município.

São Carlos. Prefeitura Municipal. (2010b). Plano Local de Habitação de Interesse Social de São Carlos (PLHIS). Etapa 2: diagnóstico: parte 1: contexto. São Carlos: Teia Casa de Criação/PROHAB. Recuperado em 6 de junho de 2019, de http://www.saocarlos.sp.gov.br/index.php/plhis-sao-carlos.html

São Carlos. Prefeitura Municipal. Fundação de Apoio à Universidade de São Paulo - FUSP. (2011). Revisão do Plano Diretor do Município de São Carlos: produto I: atualização da leitura técnica do município (141 p.). São Carlos.

Recuperado em 30 de janeiro de 2020, de

http://www.saocarlos.sp.gov.br/images/stories/pdf/2013/pde/relatorio_1.pdf

São Carlos. Prefeitura Municipal. (2016, 19 de dezembro). Lei no 18.053 , de 19 de dezembro de 2016. Dispõe sobre Empreendimentos Habitacionais de Interesse Social e sua vinculação ao "Programa Minha Casa Minha Vida" do Governo Federal, e dá outras providências. São Carlos: Diário Oficial do Município. 
São Carlos. Prefeitura Municipal. Secretaria Municipal de Habitação e Desenvolvimento Urbano - SMHDU. Comissão Executiva do Plano Diretor. (2019). Processo de elaboração do Plano Diretor (CD-ROM). São Carlos. Recuperado em 21 de agosto de 2019, de http://apoiodidatico.iau.usp.br/projeto3/planodiretor/Conferencia_da_Cidade.pdf

São Paulo. Secretaria do Meio Ambiente. Programa BIOTA/FAPESP. (2008). Diretrizes para a conservação e restauração da biodiversidade no Estado de São Paulo (248 p.). São Paulo. Recuperado em 28 de janeiro de 2020, de https://www.sigam.ambiente.sp.gov.br/sigam3/Repositorio/222/Documentos/Diretrizes_conservacao_restaurac ao_biodiversidade.pdf

Scheidt, F. S. S., Silva, P. R., Silva, S. M. C. P., \& Hirota, E. H. (2010). Consideração de requisitos ambientais em empreendimentos habitacionais de interesse social: um estudo de caso. Ambiente Construído, 10(1), 91-106. http://dx.doi.org/10.1590/S1678-86212010000100003.

Schenk, L. B. M., \& Peres, R. B. (2014). Agentes produtores e espaços livres na forma urbana de São Carlos, SP. In Anais do IX Colóquio Quapá SEL: Forma Urbana Contemporânea Brasileira: Espaços Livres e Edificados, Produção e Apropriação. Vitória: UFES.

Schenk, L. B. M., Fantin, M., \& Peres, R. B. (2015). A revisão do plano diretor da cidade de São Carlos e as novas formas urbanas em curso. In Anais do X Colóquio Quapá-SEL: Produção e Apropriação dos Espaços Livres e da Forma Urbana. Brasília: FAUUnB.

Shimbo, L. Z. (2016). Sobre os capitais que produzem habitação no Brasil. Novos Estudos CEBRAP, 35(2), $119-133$. http://dx.doi.org/10.25091/S0101-3300201600020007.

Siqueira-Gay, J., Gallardo, A. L. C. F., \& Giannotti, M. (2019). Integrating socio-environmental spatial information to support housing plans. Cities, 91, 106-115. http://dx.doi.org/10.1016/j.cities.2018.11.010.

Sistema Ambiental Paulista - DataGEO. (2007). Identificação das unidades aquíferas do Estado de São Paulo. São Paulo: Instituto Geológico do Estado de São Paulo. Recuperado em 9 de setembro de 2019, de http://datageo.ambiente.sp.gov.br/datageofiles/Downloads/UnidadesAquiferas.rar

Soares, I. O., Azevedo, M. L. P., Stephan, Í. I. C., Carvalho, A. W. B., \& Arantes, P. T. L. (2012). A instituição de ZEIS na legislação municipal: estudo de seis cidades médias de Minas Gerais. Risco, (15), 21-37.

http://dx.doi.org/10.11606/issn.1984-4506.v0i15p21-37.

Soares, I. O., Carvalho, A. W. B., Ribeiro, G. B., Fo. \& Pinto, N. M. A. (2013). Interesses especulativos, atuação do Estado e direito à cidade: o caso do programa "Minha Casa Minha Vida" em Uberaba (MG). urbe. Urbe. Revista Brasileira de Gestão Urbana, 5(1), 119-131. http://dx.doi.org/10.7213/urbe.7789.

Stanganini, F. N., \& Lollo, J. A. (2018). 0 crescimento da área urbana da cidade da Cidade de São Carlos/SP entre os anos de 2010 e 2015: o avanço da degradação ambiental. urbe. Revista Brasileira de Gestão Urbana, 10(1, Supl 1), 118-128. http://dx.doi.org/10.1590/2175-3369.010.supl1.ao14.

Trevisan, D. P., Moschini, L. E., Dias, L. C. C., \& Gonçalves, J. C. (2018). Avaliação da vulnerabilidade ambiental de São Carlos-SP. Ra'e Ga, 44, 272-288. http://dx.doi.org/10.5380/raega.v44i0.50439.

Valença, M. M. (2014). Alternativa de provisão habitacional no Brasil e no mundo. Mercator, 13(3), 7-23. http://dx.doi.org/10.4215/RM2014.1303.0001.

Valença, M. M., \& Bonates, M. F. (2010). The trajectory of social housing policy in Brazil: from the National Housing Bank to the Ministry of the Cities. Habitat International, 34(2), 165-173.

http://dx.doi.org/10.1016/j.habitatint.2009.08.006.

Villaça, F. (2004). Uma contribuição para a história do planejamento urbano no Brasil. In C. Deák, \& S. T. R. Schiffer (Eds.), o processo de urbanização no Brasil (1. ed., pp. 169-244). São Paulo: Editora da Universidade de São Paulo.

Editor: Paulo Nascimento Neto

Recebido: Out. 28, 2019

Aprovado: Abr. 22, 2020 